\title{
Blood glycaemic variations in patients with type 2 diabetes mellitus treated with different premixed insulin analogues therapy
}

 \\ ${ }^{1}$ Department of Endocrinology, Nanjing First Hospital, Nanjing Medical University, Nanjing, China \\ ${ }^{2}$ Department of Nursing Faculty, Nanjing Health School, Nanjing, China \\ ${ }^{3}$ National Heart Research Institute Singapore, National Heart Centre Singapore, Singapore \\ * The three authors contributed equally
}

\begin{abstract}
Objective: To identify potential responders in glycaemic variations to different premixed insulin analogues in penitents with type 2 diabetes mellitus (T2DM) in Chinese population.

Methods: A total of 102 patients with longstanding T2DM were admitted to hospital. After baseline data were collected, patients received therapy with continuous subcutaneous insulin infusion (CSII) for 7 days. After 2 days of premixed insulin titration, patients were randomized to groups receiving either Novo Mix 30 or Humalog Mix 50 thrice-daily for 2 days. Then patients were crossed over for another 2 days. All patients were subjected 4 consecutive days continuous glucose monitoring (CGM) during the 4 days cross over study period.

Results: There were no differences in the 24-hrs mean blood glucose (MBG), the 24-h mean amplitude of glycemic excursions (MAGE), the time spent in hyperglycemia and the incremental area under curve (AUC) of either hyperglycemia or hypoglycemia within the two arms. Although CGM data showed that patients in Humalog Mix 50 arm experienced lower blood glucose concentrations in 1300 o'clock than that in Novo Mix 30 arm. Our data indicate that patients with T2DM treated with Mix 30 had similar blood glucose fluctuations when compared with that of Mix 50.
\end{abstract}

\section{Introduction}

Many people with type 2 diabetes mellitus (T2DM) are still struggling to keep their blood glucose values in the target range. For patients in whom treatment with oral antihyperglycemic agents (OHAs) has failed, basal insulin is often recommended as the initial insulin therapy in Western countries [1], while premixed insulin analogues are an optional choice as the starter insulin for Asian patients [2,3]. A 24 week study shows that the thrice-daily premixed insulin analogue therapy achievement is non-inferior to basal-bolus therapy in the change of $\mathrm{HbAlc}$ from baseline in Asian patients with T2DM after optimal glycaemic control cannot be achieved by initial insulin therapy [4].

The clinical characteristics of T2DM in China seem to be quite different from those of Western countries. Nearly half newly diagnosed T2DM patients with only abnormal postprandial glucose concentrations [2], and isolated postprandial hyper glyceamia are more prominent in Chinese patients compared to white patients $[2,5]$. Thus, a mixture of rapid-acting and intermediate-acting insulin analogues are needed to overcome the increased postprandial glucose challenge. Premixed insulin analogues containing both basal and prandial insulin, with fasting and postprandial glucose concentration more closely mimic physiological insulin secretion. Consequently, premixed insulin analogue formulations combined at different blend ratios (biphasic insulin as part 70/30, Humalog Mix 25 and Humalog Mix 50) have become widely used in the Chinese population.
In this study, we performed continuous glucose monitoring (CGM) in patients with T2DM who treated with Mix 30 or Mix 50, to compare which premixed insulin analogue formulations smooth blood glucose fluctuations better.

\section{Methods}

A total of 102 patients with T2DM were admitted to hospital. After fasting blood samples were collected for measuring FBG and insulin, patients received therapy with continuous subcutaneous insulin infusion (CSII) for correction of hyperglycaemia. After 2 days of premixed insulin titration, patients were then randomized to receive either Novo Mix 30 (Novo Nordisk, Bagsværd, Denmark) or Humalog Mix 50 (humalog ${ }^{\circledR}$ Mix $50^{\mathrm{TM}}$, Eli Lilly and Company, IN, USA) thricedaily for 2 days. Then patients were crossed over to the other study arm for another 2 days. All subjects were instructed to maintain a similar level of physical activity and received meals consisting of the

Correspondence to: Jian-hua Ma, MD, PhD., Department of Endocrinology, Nanjing First Hospital, Nanjing Medical University, Nanjing, China, E-mail: majianhua@china.com

Key words: type 2 diabetes mellitus, premixed insulin analogues, glycaemic variations

Received: September 29, 2016; Accepted: October 26, 2016; Published: October 31,2016 
same nutritional value, and equivalent carbohydrate intake during the study. The patients, aged 18-75 years with a body mass index (BMI), calculated as weight in kilograms divided by the square of height in meters, $18-35 \mathrm{~kg} / \mathrm{m}^{2}$, and $\mathrm{HbA}_{1 \mathrm{c}}$ range $9.0-12.0 \%$. Patients were excluded if they had acute or severe chronic diabetic complications, serious systemic disease, or an assessment by the researchers were not suitable to participate were excluded [6,7]. The study was approved by the ethics committee of Nanjing First Hospital. Written informed consent was obtained from the patients prior to the study.

After five to seven days of CSII therapy, all patients achieved euglycemia control (the fasting capillary blood glucose was less than $6.1 \mathrm{mmol} / \mathrm{L}$ and capillary blood glucose at $2 \mathrm{~h}$ after each of three meals was less than $8.0 \mathrm{mmol} / \mathrm{L}[7,8]$. Then Novo Mix 30 or Humalog Mix 50 thrice-daily was administered to all patients. The premixed insulin analogue dose titration period was 2 days. Initial Pre-mixed insulin analogue doses were calculated as $0.4-0.5 \mathrm{IU} / \mathrm{kg}$, and doses were subsequently adapted according to plasma glucose values obtained by self-monitoring. Investigators administered titrated insulin doses on an individual-patient basis at the titration algorithm (if the fasting blood glucose level was less than $4.4 \mathrm{mmol} / \mathrm{L}$ ), the insulin dose was reduced 2 units; if the fasting blood glucose level was within 4.4 to 6.1 $\mathrm{mmol} / \mathrm{L}$, the insulin dose was unchanged; if the fasting blood glucose level was within 6.2 to $7.8,7.9$ to 10.0 , and $>10.0 \mathrm{mmol} / \mathrm{L}$, the insulin dose was increased subsequently by 2,4 , and 6 units, respectively). After 2 days of titration, pre-mixed insulin doses remained unchanged and were recorded. Patients were then randomized to receive either Novo Mix 30 or Humalog Mix 50 thrice-daily for 2 days. Then patients were crossed over to the other study arm for another 2 days.

All patients were subjected 4 consecutive days CGM (Medtronic Incorporated, Northridge, USA) in hospital by the specialist nurse during the 4 days cross over study period. Shortly, the CGM sensor was subcutaneously embedded at Day 0 around 16:00-17:00 PM. The patients continued with the sensors for 4 consecutive days, if CGM was going well. Subjects were instructed to keep the sensor fixed and waterproof. The study nurse inputted at least 4 calibration readings per day. At Day 4, around 16:00-17:00 PM, subjects had the sensor removed, and the CGMS data were saved by the investigator.

The $24 \mathrm{~h}$ mean blood glucose (MBG), $24 \mathrm{~h}$ mean amplitude of glycemic excursions (MAGE), the percentage time duration (\%) and the incremental area under curve (AUC) of plasma glucose $>10.0$ $\mathrm{mmol} / \mathrm{L}$ and $<3.9 \mathrm{mmol} / \mathrm{L}$ was calculated by software given Medtronic Incorporated, and hypoglycemia episodes were also recorded. MAGE was calculated for each patient by measuring the arithmetic mean of the ascending and descending excursions between consecutive peaks and nadirs for the same $24 \mathrm{~h}$ period, and only absolute excursion values $>1$ SD were considered [9].

The primary endpoint was the differences of 24-h MAGE in each premixed insulin analogue group. Secondary endpoints were the hourly mean blood glucose concentrations, the 24-h MBG, the AUC and the time spent in hypoglycaemia and hyperglycaemia were also analyzed.

\section{Statistical analysis}

Statistical analysis was performed using SPSS software (version 17.0; SPSS, Inc., Chicago, IL). Shapiro-Wilk test was used to assess the distribution of data. Normally distributed and continuous variables are presented as mean (standard deviation, SD). Non-normally distributed variables were presented as median (IQR) and logarithmically transformed before analysis. The independent samples $t$-test was used to compare each group's difference. Bonferroni correction was followed. $P$ values were two-tailed with a significance level of $5 \%$.

\section{Results}

There were 102 patients who met the inclusion criteria (52 men and 50 women; mean age, $59.42 \pm 11.73$ years; mean BMI, $23.00 \pm 7.25 \mathrm{~kg} /$ $\mathrm{m}^{2}$; mean duration of diabetes, $6.59 \pm 6.20$ years; mean HbAlc $9.82 \pm$ $2.59 \%$, mean fasting plasma glucose $11.62 \pm 3.36 \mathrm{mmol} / \mathrm{L}$; and mean insulin dose, $0.60 \pm 0.31 \mathrm{IU} / \mathrm{Kg}^{\star}$ Day) were admitted to the study. All patients were admitted to the hospital and completed the study.

During the 4 days cross over period, patients received the same doses either Novo Mix 30 or Humalog Mix 50 thrice-daily, with the mean premixed insulin analogue doses were $0.59 \pm 0.30 \mathrm{IU} / \mathrm{Kg}^{\star}$ Day.

There were no differences in the 24-hrs MBG, the MAGE, the time spent in hyperglycemia and the incremental AUC of hyperglycemia, and the time spent in hypoglycemia and the incremental AUC of hypoglycemia within the two arms (Table 1). Although, CGM data showed that patients in Humalog Mix 50 arm experienced lower blood glucose concentrations in 1300 o'clock than that in Novo Mix 30 arm $(9.47 \pm 2.46$ vs. $10.26 \pm 2.70, P=0.03$ ) (Figure 1 ).

To identify he patients who had good responses to the premixed insulin analogues, the stratified analyses were performed. There were no differences in the above mentioned parameters within the two arms in male and female subgroups (Table 2 and 3). Also, the blood glucose fluctuation parameters in younger ( $<60$ years) and older ( $\geq 60$ years) patient subgroups did not differ to the two premixed insulin analogues (Table 4 and 5).

\section{Discussion}

Our data verified an observation that longstanding T2DM in China treated with Novo Mix 30 achieved similar blood fluctuations compared with that of Humalog Mix 50 therapy. Although patients in Humalog Mix 50 arm had more smooth blood glucose concentrations after lunch time.

Table 1. The blood glucose fluctuation parameters in all subjects.

\begin{tabular}{|l|c|c|c|}
\hline \multirow{2}{*}{\multicolumn{1}{|c|}{ Item }} & \multicolumn{3}{|c|}{ All patients (102) } \\
\cline { 2 - 4 } & Humalog Mix 50 & Novo Mix 30 & P value \\
\hline 24 h MBG (mmol/L) & $8.52 \pm 1.58$ & $8.58 \pm 1.62$ & 0.79 \\
\hline SDBG (mmol/L) & $2.13 \pm 0.74$ & $2.25 \pm 0.71$ & 0.23 \\
\hline MAGE (mmol/L) & $5.54 \pm 2.23$ & $5.40 \pm 2.09$ & 0.65 \\
\hline Duration above high limit (\%) & $25.61 \pm 22.09$ & $29.59 \pm 22.14$ & 0.20 \\
\hline Duration below low limit (\%) & $1.47 \pm 3.70$ & $1.43 \pm 3.49$ & 0.94 \\
\hline $\begin{array}{l}\text { Glucose area above high limit } \\
(>10.0 \text { mmol/L*Day) }\end{array}$ & $0.61 \pm 0.73$ & $0.70 \pm 0.71$ & 0.39 \\
\hline $\begin{array}{l}\text { Glucose area below low limit } \\
(<3.9 \text { mmol/L*Day) }\end{array}$ & $0.007 \pm 0.029$ & $0.006 \pm 0.028$ & 0.81 \\
\hline
\end{tabular}

Table 2. The blood glucose fluctuation parameters in male patients

\begin{tabular}{|l|c|c|c|}
\hline \multirow{2}{*}{\multicolumn{1}{|c|}{ Item }} & \multicolumn{3}{c|}{ Male (52) } \\
\cline { 2 - 4 } & Humalog Mix 50 & Novo Mix 30 & P value \\
\hline $24 \mathrm{~h} \mathrm{MBG} \mathrm{(mmol/L)}$ & $8.25 \pm 1.39$ & $8.23 \pm 1.37$ & 0.95 \\
\hline SDBG (mmol/L) & $2.14 \pm 0.73$ & $2.30 \pm 0.77$ & 0.27 \\
\hline MAGE (mmol/L) & $5.60 \pm 2.21$ & $5.81 \pm 2.21$ & 0.64 \\
\hline Duration above high limit (\%) & $21.62 \pm 18.83$ & $25.42 \pm 19.67$ & 0.32 \\
\hline Duration below low limit (\%) & $2.06 \pm 4.47$ & $2.13 \pm 4.31$ & 0.93 \\
\hline $\begin{array}{l}\text { Glucose area above high limit } \\
(>10.0 \text { mmol/L*Day) }\end{array}$ & $0.47 \pm 0.54$ & $0.56 \pm 0.63$ & 0.43 \\
\hline $\begin{array}{l}\text { Glucose area below low limit } \\
(<3.9 \text { mmol/L*Day) }\end{array}$ & $0.010 \pm 0.036$ & $0.010 \pm 0.036$ & 1 \\
\hline
\end{tabular}


Table 3. The blood glucose fluctuation parameters in female patients.

\begin{tabular}{|l|c|c|c|}
\hline \multirow{2}{*}{\multicolumn{1}{|c|}{ Item }} & \multicolumn{3}{|c|}{ Female (50) } \\
\cline { 2 - 4 } & Humalog Mix 50 & Novo Mix 30 & P value \\
\hline 24 h MBG (mmol/L) & $8.81 \pm 1.73$ & $8.95 \pm 1.78$ & 0.69 \\
\hline SDBG (mmol/L) & $2.12 \pm 0.75$ & $2.20 \pm 0.65$ & 0.56 \\
\hline MAGE (mmol/L) & $5.47 \pm 2.27$ & $4.97 \pm 1.89$ & 0.24 \\
\hline Duration above high limit (\%) & $29.76 \pm 24.53$ & $33.92 \pm 23.87$ & 0.39 \\
\hline Duration below low limit (\%) & $0.86 \pm 2.60$ & $0.70 \pm 2.17$ & 0.74 \\
\hline $\begin{array}{l}\text { Glucose area above high limit } \\
(>10.0 \text { mmol/L*Day) }\end{array}$ & $0.76 \pm 0.87$ & $0.84 \pm 0.77$ & 0.62 \\
\hline $\begin{array}{l}\text { Glucose area below low limit } \\
(<3.9 \text { mmol/L*Day) }\end{array}$ & $0.004 \pm 0.020$ & $0.002 \pm 0.014$ & 0.56 \\
\hline
\end{tabular}

Table 4. The blood glucose fluctuation parameters in younger patients $(<60$ years $)$.

\begin{tabular}{|l|c|c|c|}
\hline \multirow{2}{*}{\multicolumn{1}{|c|}{ Item }} & \multicolumn{3}{|c|}{ Younger (52) } \\
\cline { 2 - 4 } & Humalog Mix 50 & Novo Mix 30 & P value \\
\hline 24 h MBG (mmol/L) & $8.05 \pm 1.40$ & $8.03 \pm 1.33$ & 0.93 \\
\hline SDBG (mmol/L) & $2.06 \pm 0.76$ & $2.22 \pm 0.80$ & 0.29 \\
\hline MAGE (mmol/L) & $5.28 \pm 2.05$ & $5.48 \pm 2.34$ & 0.64 \\
\hline Duration above high limit (\%) & $19.78 \pm 21.36$ & $22.06 \pm 17.18$ & 0.55 \\
\hline Duration below low limit (\%) & $2.20 \pm 4.64$ & $1.94 \pm 4.10$ & 0.76 \\
\hline $\begin{array}{l}\text { Glucose area above high limit } \\
(>10.0 \text { mmol/L*Day) }\end{array}$ & $0.41 \pm 0.55$ & $0.48 \pm 0.54$ & 0.50 \\
\hline $\begin{array}{l}\text { Glucose area below low limit } \\
(<3.9 \text { mmol/L*Day) }\end{array}$ & $0.011 \pm 0.037$ & $0.010 \pm 0.036$ & 0.83 \\
\hline
\end{tabular}

Table 5. The blood glucose fluctuation parameters in older patients.

\begin{tabular}{|l|c|c|c|}
\hline \multirow{2}{*}{\multicolumn{1}{|c|}{ Item }} & \multicolumn{3}{c|}{ Younger (52) } \\
\cline { 2 - 4 } & Humalog Mix 50 & Novo Mix 30 & P value \\
\hline 24 h MBG (mmol/L) & $9.06 \pm 1.62$ & $9.17 \pm 1.70$ & 0.76 \\
\hline SDBG (mmol/L) & $2.21 \pm 0.71$ & $2.29 \pm 0.62$ & 0.57 \\
\hline MAGE (mmol/L) & $5.82 \pm 2.40$ & $5.31 \pm 1.81$ & 0.24 \\
\hline Duration above high limit (\%) & $32.17 \pm 21.24$ & $37.42 \pm 24.08$ & 0.26 \\
\hline Duration below low limit (\%) & $0.65 \pm 1.97$ & $0.90 \pm 2.65$ & 0.59 \\
\hline $\begin{array}{l}\text { Glucose area above high limit } \\
\text { (> 10.0 mmol/L*Day) }\end{array}$ & $0.84 \pm 0.84$ & $0.92 \pm 0.81$ & 0.61 \\
\hline $\begin{array}{l}\text { Glucose area below low limit } \\
(<3.9 \text { mmol/L*Day) }\end{array}$ & $0.002 \pm 0.014$ & $0.002 \pm 0.014$ & 0.98 \\
\hline
\end{tabular}

Near-normal glucose control is more difficult to achieve, partly because of the limitations of the glycemic profile obtained from intermittent finger pricks [10]. The intermittent finger pricks were included in a total of three fasting capillary blood glucose monitoring, and capillary blood glucose monitoring $2 \mathrm{~h}$ after each of three meals [7]. $\mathrm{HbA}_{1 \mathrm{C}}$ is very useful as evidence of long term improvement in mean glucose in the large scale clinical studies for T2DM treatment $[11,12]$. Premixed insulin analogues might result in a decreasing of $\mathrm{HbA}_{1 \mathrm{C}}$ and postprandial glucose levels compared with long-acting insulin analogues and noninsulin glucose lowering agents [13]. However, $\mathrm{HbA}_{1 \mathrm{C}}$ does not necessarily reflect daily plasma glucose fluctuations. Patients with large glucose fluctuations around a similar mean may have implications of a greater the risk for long-term diabetic complications $[14,15]$. CGM provides a unique opportunity to examine the 24-h glucose excursions in T2DM, which cannot be achieved by point-to-point glimpses of blood glucose.

China has tremendous number of T2DM patients according to a national survey performed by Yang W. et.al., in 2007 [2]. Patients with T2DM in the Chinese population are quite variable when compared to Western countries. Examples are the thrifty gene carried in Chinese people [16], the different patterns of intake of nutrients, and life style, the good responsive to oral antidiabetic agents (e.g. a-glucosidase inhibitor, sulfonylureas), the lower insulin dose requirements, and the higher remission rate of short intensive insulin therapy [17]. Most importantly, the isolated postprandial hyperglyceamia is more prominent in Chinese patients when compared to white patients $[2,5]$. Thus, thrice-daily premixed insulin analogue therapy was administered to patients with T2DM in Chinese population after optimal glycaemic control cannot be achieved by initial insulin therapy [4].

Postprandial hyperglycemia, and acute glucose fluctuations may be important as independent risk factors for cardiovascular disease in patients with onset T2DM [18], the overproduction of superoxide by the mitochondrial electron-transport chain, which induces a subsequent nitrosative stress [19], and more specifically, the glucose fluctuations during postprandial periods [20].

Premixed insulin analogues were more effective than longacting insulin analogues in decreasing postprandial glucose levels for containing component (e.g. Novo mix 30 contains $70 \%$ insulin aspart isophane, Humalog Mix 50 contains $50 \%$ insulin lispro protamine) controlling preprandial blood glucose $[13,21]$. In the present pilot study, we expected to see a more reduction of postprandial plasma glucose values in Humalog Mix 50 arm in patients with longstanding T2DM for Humalog Mix 50 which contains more component lowering postprandial plasma glucose concentrations than Novo mix 30 . Our data showed a remarkable improved post lunch blood glucose concentrations in Humalog Mix 50 compared with that of Novo Mix 30. However, we did not observe the differences in blood glucose levels in post-breakfast and post-dinner. We addressed this as our limitation for we have no additional data to interpret this phenomenon. Study shows that Mix 30 might have advantages over Mix 50 in controlling fasting glucose concentration [22]. However, we did not observe the differences in other parameters of blood glucose fluctuations, such as MAGE, $24 \mathrm{~h} \mathrm{MBG}$, the SD of $24 \mathrm{~h} \mathrm{MBG}$ (SDBG), the incremental AUC, and the incremental AUC in the two arms.

Our study still has other limitations. First, the study only observed Chinese population, so the situation might not be the same for other populations. Second, the stratified sample size was relatively modest. Third, we did not observe for a long time period of time.

In conclusion, our data indicate that patients with longstanding T2DM treated with Mix 30 achieved similar blood glucose fluctuations compared with that of Mix 50.

\section{Author's contribution}

JH. M., and L.Y. contributed to the conception and design of the study. FF. L., Y. Z., T. L., and WL. Z. contributed to the Conduct/data collection. XF. S., T. L., and JD. W. contributed to data analysis. FF. L., JH. M., and L.Y. contributed to the final manuscript writing.

\section{Funding}

This research was funded by Nanjing Public Health Bureau Project (No. YKK11110) and Jiangsu Provincial Department of Science and Technology Project (No. BL2014010).

\section{References}

1. Inzucchi SE, Bergenstal RM, Buse JB, Diamant M, Ferrannini E, et al. (2012) Management of hyperglycemia in type 2 diabetes: a patient-centered approach: position statement of the American Diabetes Association (ADA) and the European Association for the Study of Diabetes (EASD). Diabetes care 35: 1364-1379. [Crossref]

2. Yang W, Lu J, Weng J, Jia W, Ji L, et al. (2010) Prevalence of diabetes among men and women in China. N Engl J Med 362: 1090-1101. [Crossref] 
3. Qiao Q, Nakagami T, Tuomilehto J, Borch-Johnsen K, Balkau B, Iwamoto Y, et al. (2000) Comparison of the fasting and the 2-h glucose criteria for diabetes in different Asian cohorts. Diabetologia 43: 1470-1475.

4. Jia W, Xiao X, Ji Q, Ahn KJ, Chuang LM, Bao Y, et al. (2015) Comparison of thricedaily premixed insulin (insulin lispro premix) with basal-bolus (insulin glargine oncedaily plus thrice-daily prandial insulin lispro) therapy in east Asian patients with type 2 diabetes insufficiently controlled with twice-daily premixed insulin: an open-label, randomised, controlled trial. Lancet Diabetes Endocrinol 3: 254-262. [Crossref]

5. Anonymous (1998) Will new diagnostic criteria for diabetes mellitus change phenotype of patients with diabetes? Reanalysis of European epidemiological data. DECODE Study Group on behalf of the European Diabetes Epidemiology Study Group. BMJ 317: 371-375. [Crossref]

6. Ziegler R, Tubili C, Chico A, Guerci B, Lundberg E, et al. (2013) ProAct study: new features of insulin pumps improve diabetes management and glycemic control in patients after transition of continuous subcutaneous insulin infusion systems. Diabetes Technol Ther 15: 738-743. [Crossref]

7. Weng J, Li Y, Xu W, Shi L, Zhang Q, et al. (2008) Effect of intensive insulin therapy on beta-cell function and glycaemic control in patients with newly diagnosed type 2 diabetes: a multicentre randomised parallel-group trial. Lancet 371: 1753-1760. [Crossref]

8. Schnell O, Mertes G, Standl E (2007) Acarbose and metabolic control in patients with type 2 diabetes with newly initiated insulin therapy. Diabetes Obes Metab 9: 853-858. [Crossref]

9. Service FJ, Molnar GD, Rosevear JW, Ackerman E, Gatewood LC, et al. (1970) Mean amplitude of glycemic excursions, a measure of diabetic instability. Diabetes 19: 644655. [Crossref]

10. Boland E, Monsod T, Delucia M, Brandt CA, Fernando S, et al. (2001) Limitations of conventional methods of self-monitoring of blood glucose: lessons learned from 3 days of continuous glucose sensing in pediatric patients with type 1 diabetes. Diabetes care 24: 1858-1862. [Crossref]

11. Anonymous (2000) Retinopathy and nephropathy in patients with type 1 diabetes four years after a trial of intensive therapy. The Diabetes Control and Complications Trial/ Epidemiology of Diabetes Interventions and Complications Research Group. $N$ Engl J Med 342: 381-389. [Crossref]
12. Anonymous (1998) Intensive blood-glucose control with sulphonylureas or insulin compared with conventional treatment and risk of complications in patients with type 2 diabetes (UKPDS 33). UK Prospective Diabetes Study (UKPDS) Group. Lancet 352(9131):837-853. [Crossref]

13. Qayyum R, Bolen S, Maruthur N, Feldman L, Wilson LM, et al. (2008) Systematic review: comparative effectiveness and safety of premixed insulin analogues in type 2 diabetes. Ann Intern Med 149: 549-559. [Crossref]

14. Nathan DM, Kuenen J, Borg R, Zheng H, Schoenfeld D, et al. (2008) Translating the A1C assay into estimated average glucose values. Diabetes Care 31: 1473-1478. [Crossref]

15. Del Prato S. (2002) In search of normoglycaemia in diabetes: controlling postprandia glucose. International journal of obesity and related metabolic disorders: Journal of the International Association for the Study of Obesity. $26-17$.

16. NEEL JV (1962) Diabetes mellitus: a "thrifty" genotype rendered detrimental by "progress"? Am J Hum Genet 14: 353-362. [Crossref]

17. DeVries JH (2013) Intensive insulin therapy for type 2 diabetes at diagnosis. Lancet Diabetes Endocrinol 1: 3-4. [Crossref]

18. DECODE Study Group, the European Diabetes Epidemiology Group (2001) Glucose tolerance and cardiovascular mortality: comparison of fasting and 2-hour diagnostic criteria. Arch Intern Med 161: 397-405. [Crossref]

19. Brownlee M1 (2005) The pathobiology of diabetic complications: a unifying mechanism. Diabetes 54: 1615-1625. [Crossref]

20. Monnier L, Mas E, Ginet C, Michel F, Villon L, et al. (2006) Activation of oxidative stress by acute glucose fluctuations compared with sustained chronic hyperglycemia in patients with type 2 diabetes. JAMA 295: 1681-1687. [Crossref]

21. DeFelippis MR, Bakaysa DL, Bell MA, Heady MA, Li S, et al. (1998) Preparation and characterization of a cocrystalline suspension of [LysB28,ProB29]-human insulin analogue. J Pharm Sci 87: 170-176. [Crossref]

22. Heise T, Weyer C, Serwas A, Heinrichs S, Osinga J, et al. (1998) Time-action profiles of novel premixed preparations of insulin lispro and NPL insulin. Diabetes care 21: 800-803. [Crossref]

Copyright: (C2016 Li FF. This is an open-access article distributed under the terms of the Creative Commons Attribution License, which permits unrestricted use, distribution, and reproduction in any medium, provided the original author and source are credited. 